\title{
Negative signals for adenomyomatosis of the gallbladder upon diffusion-weighted whole body imaging with background body signal suppression/T2-weighted image fusion analysis
}

\author{
MINORU TOMIZAWA ${ }^{1}$, FUMINOBU SHINOZAKI ${ }^{2}$, KAZUNORI FUGO $^{3}$, TAKAFUMI SUNAOSHI ${ }^{2}$, \\ ERIKO SUGIYAMA ${ }^{2}$, DAISUKE KANO ${ }^{2}$, MISAKI SHITE ${ }^{2}$, RYOUTA HAGA ${ }^{2}$, YOSHIYA FUKAMIZU ${ }^{2}$, \\ SATOSHI KAGAYAMA ${ }^{2}$, RUMIKO HASEGAWA ${ }^{4}$, YOSHINORI SHIRAI ${ }^{4}$, YASUFUMI MOTOYOSHI ${ }^{5}$, \\ TAKAO SUGIYAMA $^{6}$, SHIGENORI YAMAMOTO $^{7}$, TAKASHI KISHIMOTO ${ }^{3}$ and NAOKI ISHIGE $^{8}$
}

\begin{abstract}
Departments of ${ }^{1}$ Gastroenterology and ${ }^{2}$ Radiology, National Hospital Organization Shimoshizu Hospital, Yotsukaido, Chiba 284-0003; ${ }^{3}$ Department of Molecular Pathology, Chiba University Graduate School of Medicine, Chuo, Chiba 260-8670; Departments of ${ }^{4}$ Surgery, ${ }^{5}$ Neurology, ${ }^{6}$ Rheumatology, ${ }^{7}$ Pediatrics and ${ }^{8}$ Neurosurgery, National Hospital Organization Shimoshizu Hospital, Yotsukaido, Chiba 284-0003, Japan
\end{abstract}

Received December 7, 2014; Accepted January 14, 2016

DOI: $10.3892 / \mathrm{etm} .2016 .3126$

\begin{abstract}
Differentiation between adenomyomatosis (ADM) and cancer of the gallbladder is necessary during diagnosis. Diffusion-weighted whole body imaging with background body signal suppression (DWIBS) images are able to indicate cancer and inflammation. The fusion of a DWIBS with a T2 weighted image (DWIBS/T2) facilitates both functional and anatomical investigations. In the present study, patient records and images from patients with surgically confirmed ADM from April 2012 to October 2014 were analyzed retrospectively. The enrolled patients, including 6 men (64.2 \pm 13.1 years) and 4 women $(57.3 \pm 12.4$ years $)$ were subjected to DWIBS/T2 during routine clinical practice. The diagnosis of ADM was based on magnetic resonance cholangiopancreatography, transabdominal ultrasonography, and endoscopic ultrasonography; ADM was diagnosed definitively when cystic lesions were observed, indicating the Rokitansky-Aschoff sinus. A single patient was indicated to be positive by DWIBS/T2 imaging. The Rokitansky-Aschoff sinus revealed a relatively high signal intensity; however, it was not as strong as that of the spleen. The signal intensity was also high on an apparent diffusion coefficient map, suggesting T2 shine-through. The thickened wall displayed low signal intensity. The aforementioned results indicate that ADM may be negative upon DWIBS/T2 imaging; one false positive case was determined to be ADM,
\end{abstract}

Correspondence to: Dr Minoru Tomizawa, Department of Gastroenterology, National Hospital Organization Shimoshizu Hospital, 934-5 Shikawatashi, Yotsukaido, Chiba 284-0003, Japan E-mail: nihminor-cib@umin.ac.jp

Key words: diffusion weighted imaging, magnetic resonance cholangiopancreatography, apparent diffusion coefficient, chronic cholecystitis accompanied by chronic cholecystitis. The majority of patients with ADM displayed negative findings upon DWIBS/T2 imaging, and chronic cholecystitis may cause false positives.

\section{Introduction}

Adenomyomatosis of the gallbladder (ADM) is defined as the epithelial proliferation and hypertrophy of the muscles of the gallbladder wall (1). An outpouching of the gallbladder mucosa into the thickened muscular layer is termed Rokitansky-Aschoff sinus (2). ADM may be further divided into three subtypes: Fundal, segmental and diffuse (3). A major challenge in ADM diagnosis arises from the difficulty in distinguishing the disease from gallbladder cancer (4).

Recent advances in diagnostic imaging have improved the distinction between ADM and gallbladder cancer. Contrast-enhanced endoscopic ultrasonography (EUS) is beneficial for the differential diagnosis of gallbladder wall thickening (5). High-resolution ultrasound is also advantageous for differentiating gallbladder cancers from ADM (6); however, the challenge of differentiating gallbladder cancer from ADM has yet to be resolved. A primary cause of the challenge is intratumoral cystic components, which create difficulty in discerning between gallbladder cancer and $\operatorname{ADM}(7)$.

Diffusion-weighted whole body imaging with background body signal suppression (DWIBS) images are acquired through multiple-signal averaging, pre-pulse fat suppression, and heavy diffusion weighting during free breathing (8); DWIBS is based upon diffusion-weighted imaging (DWI), which visualizes and assesses the random movement of water at the molecular level (Brownian motion) $(9,10)$. An advantage of DWIBS is that it provides a strong contrast of cancerous tissues against the adjacent non-cancerous tissues, which is useful for detection and staging, and for monitoring the response to therapy (11). A major limitation of DWIBS is that anatomical analysis may occasionally prove difficult $(12,13)$. Using a workstation, DWIBS images 
Table I. Pulse sequences used in the present study.

\begin{tabular}{|c|c|c|c|}
\hline Parameter & T1-weighted imaging & T2-weighted imaging & DWI (DWIBS) \\
\hline Sequences & GRE & SE & EPI SE \\
\hline TR, msec & Shortest & 1,000 & 11,250 \\
\hline TE, msec & First, 2.3 (out-phase); second: 4.6 (in-phase) & 90 & 83 \\
\hline 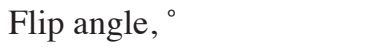 & 75 & 90 & 90 \\
\hline NSA & 1 & 1 & 4 \\
\hline Slice thickness, mm & 8 & 8 & 5 \\
\hline Slice gap & 1 & 1 & 0 \\
\hline Fat saturation & None & None & SPAIR \\
\hline Phase encoding direction & Posterior-anterior & Posterior-anterior & Posterior-anterior \\
\hline
\end{tabular}

may be overlapped with T2-weighed images (T2WIs) to create DWIBS/T2 fusion images $(11,14,15)$; these DWIBS/T2 images can clearly provide functional information about the anatomy.

Therefore, DWIBS/T2 images of ADM were analyzed in the present study in order to investigate the distinctions between ADM and gallbladder cancer.

\section{Patients and methods}

Patients. Patient records and images from April 2012 to October 2014 were analyzed retrospectively. The enrolled patients included 6 men $(64.2 \pm 13.1$ years) and 4 women $(57.3 \pm 12.4$ years). Of the 10 patients, 8 had fundal, and 2 had segmental ADM. The patients underwent DWIBS/T2 as part of routine clinical practice. A number of patients $(n=3)$ underwent surgery due to a clinical suspicion of gallbladder cancer. The surgical specimens confirmed the diagnosis of ADM. All patients underwent regular follow-up (duration, 1-27 months), and none of the patients demonstrated any evidence of gallbladder cancer. The study was submitted to the ethics committee of the National Hospital Organization Shimoshizu Hospital (Yotsukaido, China) for review and was not considered a clinical trial as it was conducted during routine clinical practice. Patient anonymity was preserved.

Diagnosis of ADM. The diagnosis of ADM was based upon imaging techniques, including computed tomography (CT; SOMATOM Emotion 16; Siemens AG, Munich, Germany), transabdominal ultrasonography (US; SSA-700A; Toshiba Medical Systems Corporation, Ohtawara, Japan), EUS (GF-UCT260; Olympus Corporation, Tokyo, Japan) and magnetic resonance cholangiopancreatography (MRCP; Philips Healthcare, DA Best, The Netherlands), with Achieva Software version 3.2.2 The diagnosis of ADM was predominately based on the visualization of the Rokitansky-Aschoff sinus by MRCP, as represented by the pearl necklace sign (16). Wall thickening $>10 \mathrm{~mm}$, disruption of the normal layers of the gallbladder wall and hypoechoic lesions in the wall were absent upon US and EUS (17). Microcysts were observed during examination using US and EUS, indicating the presence of the Rokitansky-Aschoff
Table II. Patient characteristics.

\begin{tabular}{lc}
\hline Variable & Value (mean \pm standard deviation) \\
\hline $\mathrm{WBC}, 10^{3} / \mu \mathrm{l}$ & $5.0 \pm 1.0$ \\
$\mathrm{Hb}, \mathrm{g} / \mathrm{dl}$ & $14.3 \pm 1.2$ \\
$\mathrm{CRP}, \mathrm{mg} / \mathrm{dl}$ & $0.15 \pm 0.10$ \\
$\mathrm{~T}-\mathrm{Bil}, \mathrm{mg} / \mathrm{dl}$ & $0.98 \pm 0.33$ \\
$\mathrm{ALP}, \mathrm{IU} / \mathrm{l}$ & $190 \pm 95$ \\
$\mathrm{AST}, \mathrm{IU} / \mathrm{l}$ & $20.1 \pm 5.1$ \\
$\mathrm{ALT}, \mathrm{IU} / \mathrm{l}$ & $17.6 \pm 5.4$ \\
$\mathrm{GGT}, \mathrm{IU} / \mathrm{l}$ & $26.7 \pm 14.4$ \\
$\mathrm{CEA}, \mathrm{ng} / \mathrm{ml}$ & $2.2 \pm 1.5$ \\
$\mathrm{CA} 19-9, \mathrm{U} / \mathrm{ml}$ & $12.0 \pm 8.4$
\end{tabular}

WBC, white blood cell count; $\mathrm{Hb}$, hemoglobin; CRP, C-reactive protein; T-Bil, total bilirubin; ALP, alkaline phosphatase; AST, aspartate aminotransferase; ALT, alanine aminotransferase; GGT, $\gamma$-glutamyl transpeptidase; CEA, carcinoembryonic antigen; CA19-9, carbohydrate antigen 19-9.

sinus (18). CT imaging was applied for the detection of the wall thickening (19).

Magnetic resonance imaging (MRI). All MRI examinations were performed using an 1.5 Tesla scanner (Achieva, software version 3.2.2; Philips Medical Systems B.V., Eindhoven, The Netherlands). The T1-weighted images (T1WIs), T2WIs and diffusion-weighted images were obtained with pulse sequences, as depicted in Table I. The DWIBS/T2 images were constructed with the Extended MR WorkSpace (Philips Medical Systems B.V.), and the sequences are displayed in Table I. DWI gradients were applied along the X-, $\mathrm{y}$ - and z-axes prior to and after a $180^{\circ}$ inversion pre-pulse to obtain fat-saturated, isotropic images with DWI sensitivity using the following parameters for a single stack: b value, $0 \mathrm{~mm}^{2} / \mathrm{sec}$ and $800 \mathrm{~mm}^{2} / \mathrm{sec}$; repetition time/echo time/inversion recovery, 6,960/79/150 msec; acquisition 
A

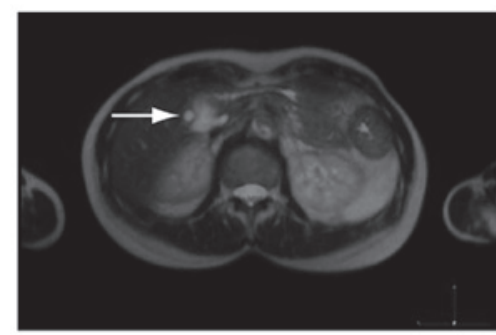

C

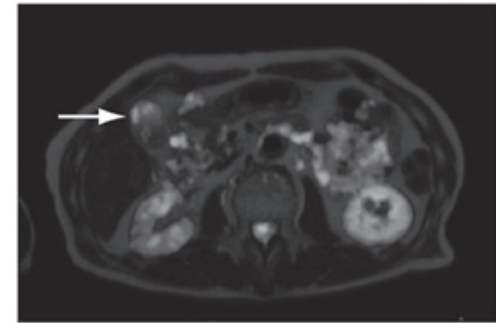

E

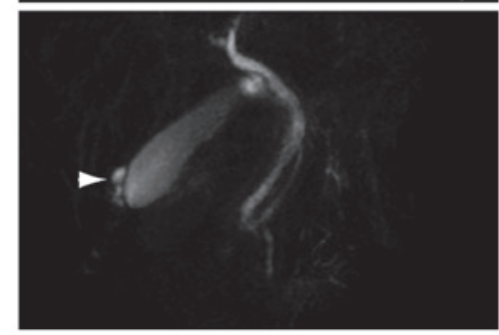

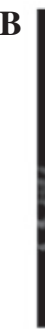

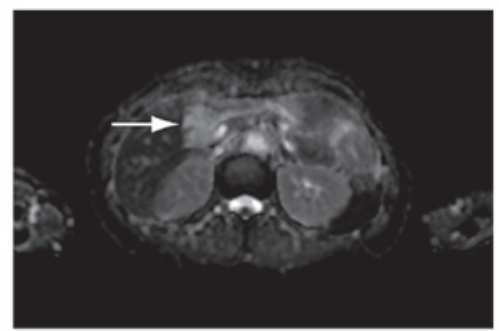

$\mathbf{D}$
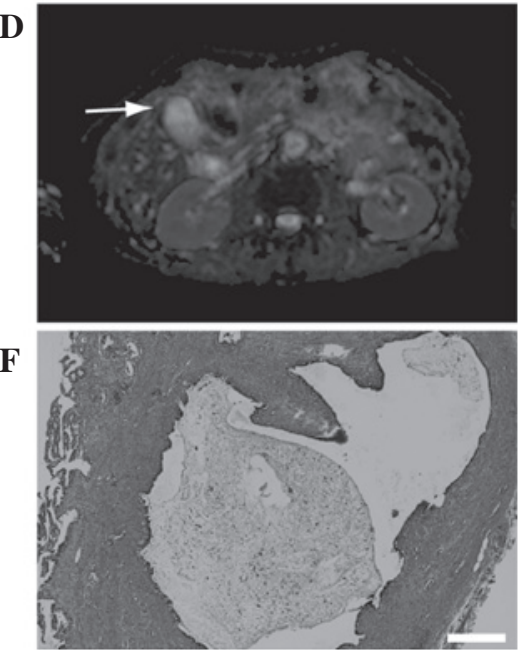

Figure 1. Diffusion-weighted whole body imaging with background body signal suppression (DWIBS)/T2-weighted image fusion (DWIBS/T2) of adenomyomatosis of gallbladder. (A and B) DWIBS/T2 observations for gallbladder wall thickening in a 65-year-old woman. High signal intensity is visible in the fundus of gallbladder (A) upon DWIBS/T2 imaging and (B) on the apparent diffusion coefficient (ADC) map, the latter indicating T2 shine-through. (C-F) DWIBS/T2 findings for gallbladder wall thickening in a 63-year-old man. (C) High signal intensity is observed in the fundus of the gallbladder upon DWIBS/T2 imaging. (D) No high signal is visible in the fundus of the gallbladder on the ADC map. The high signal intensity upon DWIBS/T2 imaging was determined as a positive finding, and suspected of malignancy. (E) Magnetic resonance cholangiopancreatography showing the pearl necklace sign. (F) Surgical specimen showing the proliferation of muscle fiber, and the dilated Rokitansky-Aschoff sinus (original magnification, $\mathrm{x} 40$; scale bar, $500 \mu \mathrm{m}$ ). Lymphocyte infiltration is observed. The patient was later diagnosed with chronic cholecystitis and adenomyomatosis.

matrix, 176x115; reconstruction matrix, 256; field of view, right/left, $530 \mathrm{~mm}$, anterior/posterior, $349 \mathrm{~mm}$, and feet/head, $226 \mathrm{~mm}$; slice thickness, $6 \mathrm{~mm}$; size of reconstructed voxel, $2.07 \times 2.08 \times 6 \mathrm{~mm}^{3}$; and 4 averages. An apparent diffusion coefficient (ADC) map was produced from the recorded ADC values in order to eliminate the possibility of T2 shine-through and to differentiate malignant lesions from non-malignant causes of restricted diffusion (20).

\section{Results}

ADM is negative upon DWBS/T2 imaging. Patient characteristics are displayed in Table II. All variables were within normal limits. Upon DWIBS/T2 imaging, only 1 patient had positive results. Cystic lesions in the thickened wall exhibited a relatively high signal intensity upon DWIBS/T2 imaging; however, the intensity was not as strong as that from the spleen (Fig. 1A). The spleen displayed high signal intensity upon DWIBS/T2 imaging. The intensity of the cystic lesion was also high on the ADC map (Fig. 1B), indicating the presence of T2 shine-through. It was determined that the cystic lesion was a Rokitansky-Aschoff sinus. Low signal intensity was observed for the thickened wall. The aforementioned results indicate that ADM may be negative upon DWIBS/T2 imaging.

ADM is concomitant with chronic cholecystitis. A high signal intensity was observed upon DWIBS/T2 imaging for a second patient (Fig. 1C); however, the patient's ADC map did not reveal any high intensity signals (Fig. 1D). It was suggested that the patient may have gallbladder cancer; however, the pearl necklace sign (21) was observed during MRCP (Fig. 1E). Due to the complexities involved in differentiating between ADM and gallbladder cancer, the patient underwent surgery. The surgical specimen revealed the presence of ADM concomitant with chronic cholecystitis (Fig. 1F). On the basis of the aforementioned findings, it was concluded that the high signal intensity observed during DWIBS/T2 imaging was a false positive.

\section{Discussion}

DWI is known to improve the accuracy of the diagnosis of gallbladder cancer (22). Upon DWI, a high signal intensity is observed for cystic lesions in ADM, indicating the presence of the Rokitansky-Aschoff sinus (22). Compared with benign lesions, gallbladder cancer displays significantly lower signal intensity on the ADC map (23). These studies indicate that a definitive diagnosis of ADM or gallbladder cancer is dependent upon the ADC values. In the present study, the Rokitansky-Aschoff sinus was negative upon DWIBS/T2 imaging, as was the thickened wall of the ADM. The ADC values or ADC map were also valuable in diagnosing T2 shine-through for the Rokitansky-Aschoff sinus, and in confirming the ADM or gallbladder cancer diagnoses. 
At present, few previous studies have reported the use of DWI for the diagnosis of ADM, and no report has been found regarding the use of DWIBS in ADM diagnosis. Ogawa et al (24) reported the use of DWI in gallbladder diseases; DWI was positive in $11 \%$ of their patients (they determined a result to be positive when a high signal was observed). There is a possibility that T2-shine through may be read as a positive result. Therefore, in the present study, the possibility of T2-shine through was omitted using a ADC map and ADM was negative with DWIBS/T2. In addition, DWIBS/T2 enabled the evaluation of signals in anatomical settings. These findings suggested that negative DWIBS/T2 results may be considered useful for the diagnosis of ADM.

The ADC values for gallbladder cancer are significantly lower, as compared with those for benign lesions (22). In the present study, only 1 of 10 patients displayed low signal intensity on the ADC map. It was suggested that the patient had gallbladder cancer; however, the surgical specimen revealed the presence of chronic cholecystitis with ADM, highlighting the difficulty in differentiating between chronic cholecystitis and ADM (4). Chronic cholecystitis is known to cause false positives in DWI (24). One patient with false positive DWI findings was diagnosed with chronic cholecystitis in the present study. Inflammation is also known to give rise to false positives in DWI (25). It was speculated that chronic cholecystitis may be the underlying cause of the false positive findings in the present case.

A limitation of the present study is that it was based upon a small number of patients. Another limitation was that the present study did not include patients with gallbladder cancer. In the future, we propose to include greater numbers of patients, in particular, those with gallbladder cancer.

In conclusion, the majority of the patients with ADM displayed negative findings upon DWIBS/T2 imaging. A patient with a false positive finding had accompanying chronic cholecystitis.

\section{References}

1. Colquhoun J: Adenomyomatosis of the gall-bladder (intramural diverticulosis). Br J Radiol 34: 101-112, 1961.

2. Williams I, Slavin G, Cox A, Simpson P and de Lacey G: Diverticular disease (adenomyomatosis) of the gallbladder: A radiological-pathological survey. Br J Radiol 59: 29-34, 1986.

3. Kim JH, Jeong IH, Han JH, Kim JH, Hwang JC, Yoo BM, Kim JH, Kim MW and Kim WH: Clinical/pathological analysis of gallbladder adenomyomatosis; Type and pathogenesis. Hepatogastroenterology 57: 420-425, 2010.

4. Kim BS, Oh JY, Nam KJ, Cho JH, Kwon HJ, Yoon SK, Jeong JS and Noh MH: Focal thickening at the fundus of the gallbladder: Computed tomography differentiation of fundal type adenomyomatosis and localized chronic cholecystitis. Gut Liver 8: 219-223, 2014.

5. Imazu H, Mori N, Kanazawa K, Chiba M, Toyoizumi H, Torisu Y, Koyama S, Hino S, Ang TL and Tajiri H: Contrast-enhanced harmonic endoscopic ultrasonography in the differential diagnosis of gallbladder wall thickening. Dig Dis Sci 59: 1909-1916, 2014.

6. Joo I, Lee JY, Kim JH, Kim SJ, Kim MA, Han JK and Choi BI: Differentiation of adenomyomatosis of the gallbladder from early-stage, wall-thickening-type gallbladder cancer using high-resolution ultrasound. Eur Radiol 23: 730-738, 2013.

7. Yoshimitsu K, Irie H, Aibe H, Tajima T, Nishie A, Asayama Y, Matake K, Yamaguchi K, Matsuura S and Honda $\mathrm{H}$ : Well-differentiated adenocarcinoma of the gallbladder with intratumoral cystic components due to abundant mucin production: A mimicker of adenomyomatosis. Eur Radiol 15: 229-233, 2005.
8. Takahara T, Imai Y, Yamashita T, Yasuda S, Nasu S and Van Cauteren M: Diffusion weighted whole body imaging with background body signal suppression (DWIBS): Technical improvement using free breathing, STIR and high resolution 3D display. Radiat Med 22: 275-282, 2004.

9. Sehy JV, Ackerman JJ and Neil JJ: Apparent diffusion of water, ions and small molecules in the Xenopus oocyte is consistent with Brownian displacement. Magn Reson Med 48: 42-51, 2002.

10. Koike N, Cho A, Nasu K, Seto K, Nagaya S, Ohshima Y and Ohkohchi N: Role of diffusion-weighted magnetic resonance imaging in the differential diagnosis of focal hepatic lesions. World J Gastroenterol 15: 5805-5812, 2009.

11. Kwee TC, Takahara T, Ochiai R, Nievelstein RA and Luijten PR: Diffusion-weighted whole-body imaging with background body signal suppression (DWIBS): Features and potential applications in oncology. Eur Radiol 18: 1937-1952, 2008.

12. Ohno Y, Koyama H, Onishi Y, Takenaka D, Nogami M, Yoshikawa T, Matsumoto S, Kotani Y and Sugimura K: Non-small cell lung cancer: Whole-body MR examination for M-stage assessment-utility for whole-body diffusion-weighted imaging compared with integrated FDG PET/CT. Radiology 248: 643-654, 2008.

13. Fischer MA, Nanz D, Hany T, Reiner CS, Stolzmann P, Donati OF, Breitenstein S, Schneider P, Weishaupt D, von Schulthess GK and Scheffel H: Diagnostic accuracy of whole-body MRI/DWI image fusion for detection of malignant tumours: A comparison with PET/CT. Eur Radiol 21: 246-255, 2011.

14. Sommer G, Wiese M, Winter L, Lenz C, Klarhöfer M, Forrer F, Lardinois D and Bremerich J: Preoperative staging of non-small-cell lung cancer: Comparison of whole-body diffusion-weighted magnetic resonance imaging and ${ }^{18} \mathrm{~F}$-fluorodeoxyglucose-positron emission tomography/computed tomography. Eur Radiol 22: 2859-2867, 2012.

15. Nechifor-Boilă IA, Bancu S, Buruian M, Charlot M, Decaussin-Petrucci M, Krauth JS, Nechifor-Boilă AC and Borda A: Diffusion weighted imaging with background body signal suppression/T2 image fusion in magnetic resonance mammography for breast cancer diagnosis. Chirurgia (Bucur) 108: 199-205, 2013.

16. Stunell H, Buckley O, Geoghegan T, O'Brien J, Ward E and Torreggiani W: Imaging of adenomyomatosis of the gall bladder. J Med Imaging Radiat Oncol 52: 109-117, 2008.

17. Kim HJ, Park JH, Park DI, Cho YK, Sohn CI, Jeon WK, Kim BI and Choi SH: Clinical usefulness of endoscopic ultrasonography in the differential diagnosis of gallbladder wall thickening. Dig Dis Sci 57: 508-515, 2012.

18. Akatsu T, Aiura K, Shimazu M, Ueda M, Wakabayashi G, Tanabe M, Kawachi S and Kitajima M: Can endoscopic ultrasonography differentiate nonneoplastic from neoplastic gallbladder polyps? Dig Dis Sci 51: 416-421, 2006.

19. Ching BH, Yeh BM, Westphalen AC, Joe BN, Qayyum A and Coakley FV: CT differentiation of adenomyomatosis and gallbladder cancer. AJR Am J Roentgenol 189: 62-66, 2007.

20. Wang Y, Miller FH, Chen ZE, Merrick L, Mortele KJ, Hoff FL, Hammond NA, Yaghmai V and Nikolaidis P: Diffusion-weighted MR imaging of solid and cystic lesions of the pancreas. Radiographics 31: E47-E64, 2011.

21. Haradome H, Ichikawa T, Sou H, Yoshikawa T, Nakamura A, Araki T and Hachiya J: The pearl necklace sign: An imaging sign of adenomyomatosis of the gallbladder at MR cholangiopancreatography. Radiology 227: 80-88, 2003.

22. Lee NK, Kim S, Kim TU, Kim DU, Seo HI and Jeon TY: Diffusion-weighted MRI for differentiation of benign from malignant lesions in the gallbladder. Clin Radiol 69: e78-e85, 2014.

23. Yoshioka M, Watanabe G, Uchinami H, Miyazawa H, Abe Y, Ishiyama K, Hashimoto M, Nakamura A and Yamamoto Y: Diffusion-weighted MRI for differential diagnosis in gallbladder lesions with special reference to ADC cut-off values. Hepatogastroenterology 60: 692-698, 2013.

24. Ogawa T, Horaguchi J, Fujita N, Noda Y, Kobayashi G, Ito K, Koshita S, Kanno Y, Masu K and Sugita R: High b-value diffusion-weighted magnetic resonance imaging for gallbladder lesions: Differentiation between benignity and malignancy. J Gastroenterol 47: 1352-1360, 2012.

25. Padhani AR, Koh DM and Collins DJ: Whole-body diffusion-weighted MR imaging in cancer: Current status and research directions. Radiology 261: 700-718, 2011. 